\title{
HOW CAN SOCIAL NETWORKS IMPROVE THE RECRUITMENT PROCESS CASE STUDY - LINKEDIN
}

\author{
Raluca Magda GEORGESCU ${ }^{a *}$, Ionuț Cătălin SAVU ${ }^{b}$, Gheorghe MILITARU ${ }^{c}$ \\ a 1development, Romania \\ ${ }^{b}$ Enel Energie Muntenia S.A., Romania \\ ${ }^{c}$ University Politehnica of Bucharest, Romania
}

\begin{abstract}
The digital era implies not only changes in the workforce, it has an even greater impact on managers 'education, and from this perspective managers' training needs to be given greater attention. Training has the main starting point for the target audience, but it is not necessary to ignore the start and initial level of the trained. Also, the education and experience of managers who are trained are equally important. In this context, the educational system needs to adapt to the needs of the digital era, not just for those who are already in college. In addition, he has to find a balance between the two worlds, the new digital one was present in order to provide a transition that would produce effects. The purpose of the current paper is to study the connection between human capital and the social networks that interfere in the human resource management, especially when it's related to the labor market and the recruitment processses. In this paperwork was used as a qualitative research method based on the analysis of more case studies in order to demonstrate that the presence of social networks in the labor market can bring advantages for both sides-employee and employer.
\end{abstract}

KEYWORDS: Human Resources Management, Linkedin, Management Evolution, Social Network.

\section{INTRODUCTION}

Regarding the definition of management in the digital era, there are several relevant views. (Petty, 2016), a recognized leader in the software and management industry, has compiled a summary of the essential skills that a person in a management position in the digital era must have.

- Technical agility. Today, management is not possible without the use of IT tools made available by the digital age.

- Agility of data. The multitude of information and access to it requires data processing capabilities.

- Project Management. A manager needs to know how to lead teams, processes and projects.

- Social abilities. Management becomes inefficient if it does not have a structured and upto-date horizontal and vertical communication.

Essentially, the message sent by specialists is synthesized through the "Be smart and flexible" call, two features that will define individual success in the digital age. In a world where everything is dynamic, digitized the technological information must be used to make decisions and coordinate work. Thus, the main necessity is that the management must not be interrupted, thus ensuring the mobility that is so necessary for a manager.

\footnotetext{
* Corresponding author. E-mail address: rgeorgescu3@gmail.com
} 
In specialized literature, there have been many studies that have investigated the human resource management, but few have investigated the recruitment process from a social network perspective, social networks that are nowadays often encountered in everyday activities. Since social media channels have this amazing capability, some organizations are embracing its usage with the expected result of targeting potential employees. The use of social media such as blogs, networking sites and micro-blogging is on the rise through the enterprise environment. The exchange of information facilitates the development of ideas by conversing users as they become socially connected worldwide.

The first and the second part of the paper analysis the labor market after the appearance of social networks in the working environment and how the digital era influence the exchanges of the offers and requests in the relation between employee and employer. Human resources specialists must adapt to these changes in the behavior of young people and, more precisely, of future employees. They need to adopt modern recruitment strategies, improve the quality of the work environment and the organizational environment. The third part includes a specific case study on the recruitment platform that is used worldwide - Linkedin.

\section{ANALYSIS OF LABOR MARKET AND THE NEED FOR DIGITAL COMPETENCES}

What jobs will be searched in 2025? There are five areas of expertise that experts recommend, as well as some of the categories with the highest increases in job demand, defined by the Bureau of Labor Statistics (BLS) and other associated sources (Morgan, 2016).

Knowledge of technology and computer. It is no surprise that technological skills will still be on the lookout, namely the ability to handle massive amounts of information that we process individually each day to identify patterns of work and to unite them all unitary. Posts related to these qualities are defined by program developer, a job that will grow in demand by $18.8 \%$ by 2024 , while computer analyst posts will grow by $20.9 \%$ by 2024 . Posts market research analyst and specialist marketing, which also require analytical qualities, will have an increase of $18.6 \%$ (Fidler, 2015).

Medical care. The life expectation of the population is increasing, so every aspect of the health sector is growing. While telemedicine, robotic surgical equipment and other forms of automation redefine the way healthcare is provided, demand for caregivers / nurses will increase as we aim to provide healthcare for the widest range of population - a population that is growing and lives longer. It will take a long time for robots to have human skills, such as social and emotional intelligence or intercultural competence (Challenger, 2013). Related posts include medical technicians, physical therapist, workplace ergonomics experts, medical secretaries, and nurses will be at high demand. Also, home healthcare jobs are expected to increase by $38.1 \%$.

Social intelligence and knowledge of new media. Robots will take a long time to develop their human abilities, such as social and emotional intelligence, and intercultural competencies that are extremely valuable in a world where everyone can work at any time with someone in the Philippines in less than an hour. Virtual collaboration is also now an asset for those who know the online environment. Also, knowing the new media - understanding the various media platforms and how we communicate best with them. Associated jobs, such as sales, marketing and customer service, are expected to grow between $6.4 \%$ and $18.6 \%$ by category by 2024 . (Fidler, 2015).

Adaptability and business knowledge together with associated jobs such as management analysts, accountants and auditors will double as required by 2024. Digital natives are part of the generation born during or after the introduction of digital technology. While individuals from older generations remember how to organize, plan and interact with each other without mobile devices, computers or the internet, digital natives have used these technologies since they were children. 
In Romania, digital technology is extensively used, mainly for social networks. In this case, Romania ranks $3^{\text {rd }}$ among the other EU Member States, but with regard to the use of digital technology in access to public services, it is among the last places. On the one hand, youth unemployment is high, at $4.6 \%$ and, on the other hand, youth unemployment in IT \& C does not exist.

Due to changes in people's behavior as a consequence of the effects of the digital world, Romanians want to be more and more technological active, to have access to information and transparency from companies, and be able to connect with their work from any corner of the world. When choosing the future employer, individuals look at companies' offer especially from these points of view (Edelhauser et al., 2014).

The future belongs to those who are currently in school and will start work in 2030. The skills that will be used in the future are formed at the age of 13-14 years. After this age, they will only improve their knowledge. Romania will have to take an example from foreign countries where people in the first classes are taught to use the computer, starting with the basics of programming. At the same time, our country is overwhelmed by technology, and adults have to adapt and keep up with the progress of labor demand and the new requirements.

How the new platforms help develop business relationships? The answer is that people working in the field of human resources have begun to diversify their search, recruitment, recruitment and selection methods for the most suitable potential employees due to the almost limitless opportunities offered by the online environment that is constantly developing. Social networks such as Facebook, Instagram, Twitter and even LinkedIn have become the most conducive environments for attracting potential employees.

The use of smartphones phones and applications takes a large part of the time of people of all ages, but especially young people aged 15-30 years. By using applications to the detriment of the official site, which often does not offer the same speed, accessibility and functionality as a dedicated application. HR staff has understood the trends that young graduates have in the past and have taken advantage of this information to make the recruitment process as easy, fast and sometimes even more enjoyable as possible for potential employees.

\section{THE ROLE AND IMPORTANCE OF SOCIAL NETWORKS IN THE DEVELOPMENT OF HUMAN CAPITAL}

Human resource management has undergone numerous changes since its emergence as a distinct department within many companies. With the modernization of the business world and the development of technology, HR management has undergone changes to keep pace and deliver effective solutions to the prospects of possible future employees. It is known that a firm can grow only with the help of its employees (Emilian et al., 2003).

Due to the fact that people spend more and more time online and especially on social networks, HR managers have turned their attention to the online environment to catch the attention of as many people as possible, even those who are not looking for a job, but they just want to relax or get in touch. Social networks have become a very good environment for those who want to capture the attention of the $\mathrm{Z}$ and $\mathrm{Y}$ generations who spend a great deal of time online and especially young people, fresh graduates who get information about jobs and want to apply to as many open positions. The online environment offers people the opportunity to stay informed and keep up-to-date with news in the areas that interest them. They are organized into groups that have the same interests as themselves, becoming a phenomenon called "fandom", finding people with whom they can exchange impressions and tips and even meet in the real world. 
About the recruitment processes we can observe that have become too long, $47 \%$ of companies support, and at the same time more difficult than 2 years ago (42\%). Recruitment time for open positions is between 30 and 60 days for nearly half of respondents, and 14\% say they are able to hire after 90 days or more. One third of companies, especially small and medium-sized ones, say the recruitment process does not exceed 30 days, and only 5\% occupy a position in less than two weeks. When starting the recruitment process for a new position, companies rely heavily on online recruitment platforms (93\%), on the recommendations from the existing team $(67 \%)$, on social networks (40\%), but and on direct applications on the company's website (26\%). However, in order to find valuable candidates, companies have increasingly diversified their methods of attracting them. The concept of engagement will be redefined due to skills shortages, demographic changes and a massive increase in virtual workplaces and job placements based on punctual projects.

Benefits have been seen particularly in the areas of recruitment and brand awareness. Not only did it have a positive impact, but it is also inexpensive. Human resources specialists are challenged to do more with less and for this very reason using social media as a tool for recruitment are a cost-effective way.

Speaking about cost-effective, it can be seen both ways - from the point of view of the employer, but also for the employee: the social media networks allow the candidate pool to look for the potential employers that geographically farther and they cannot travel to them due to practical and financial difficulties to approach the employers. The employers also said that they are now more able to identify the number of unqualified applicants that were greatly impacting their recruitment practices. Not only that using social media is inexpensive but the key to grasp the attention of the targeted audience is to have an iterative approach by using different social media channels along with traditional recruitment tactics to reach out to a larger demographics. Social networking sites afford candidates the opportunity to create a solid profile subsequently assisting with the recruitment process, in particular the sourcing process, by giving the employer an impression of a candidate's overall cultural fit as well as their technical competence, and by this the big advantage of using social media is it's accessibility for everybody, from any part of the world.

Agility and flexibility are important to coincide with fluctuating economic conditions and this is when having a clearly defined social networking strategy will pay dividends, both from a candidate generation and employment brand perspective. The speed at which social media tools could grasp the attention of the targeted compared to traditional methods is zero to none.

\section{RESEARCH METHOD}

Using the qualitative research method, the objective of this paper is to highlight the advantages of the social platforms in the recruitment process.

A modern recruitment strategy includes the use of the online environment and recruitment platforms, and Linkedin is just an example. Recruiters go a little closer to attracting candidates in the environments where they spend their time, using friendly and less formal communication methods. The digital environment is the perfect channel for communication and interaction with potential future employees.

\subsection{Case study on using Linkedin network}

Linkedin appeared in the online environment as a site that anyone can upload a resume and so can be found easier by head-hunters who view applications every day looking for ideal employees to fit their needs in terms of education and performance. 
Companies can create a profile to provide candidates with information about their field of activity, but also about the positions they have opened in the various departments (Noela, 2018). Starting from the idea of connecting professionals and entrepreneurs, founder Reid Hoffman has created the ideal meeting environment. He believes that specialized artificial intelligence will transform management from a simple art into a combination of art and science and allow us to apply data science to human interactions at work.

Linkedin's social networking features include the fact that a candidate can apply for jobs, stay up to date with what new jobs appear every day or week, create a profile similar to an online CV, or join in groups of people with the same interests.

In essence, adherents to the platform can communicate with people from the other end of the world, apply to any job they want and put in a favorable light within minutes to be easily found by human resources.

\section{How People Get Jobs - 2015 \& 2016}

Total Talent Market by Job Hunting Status and Demand

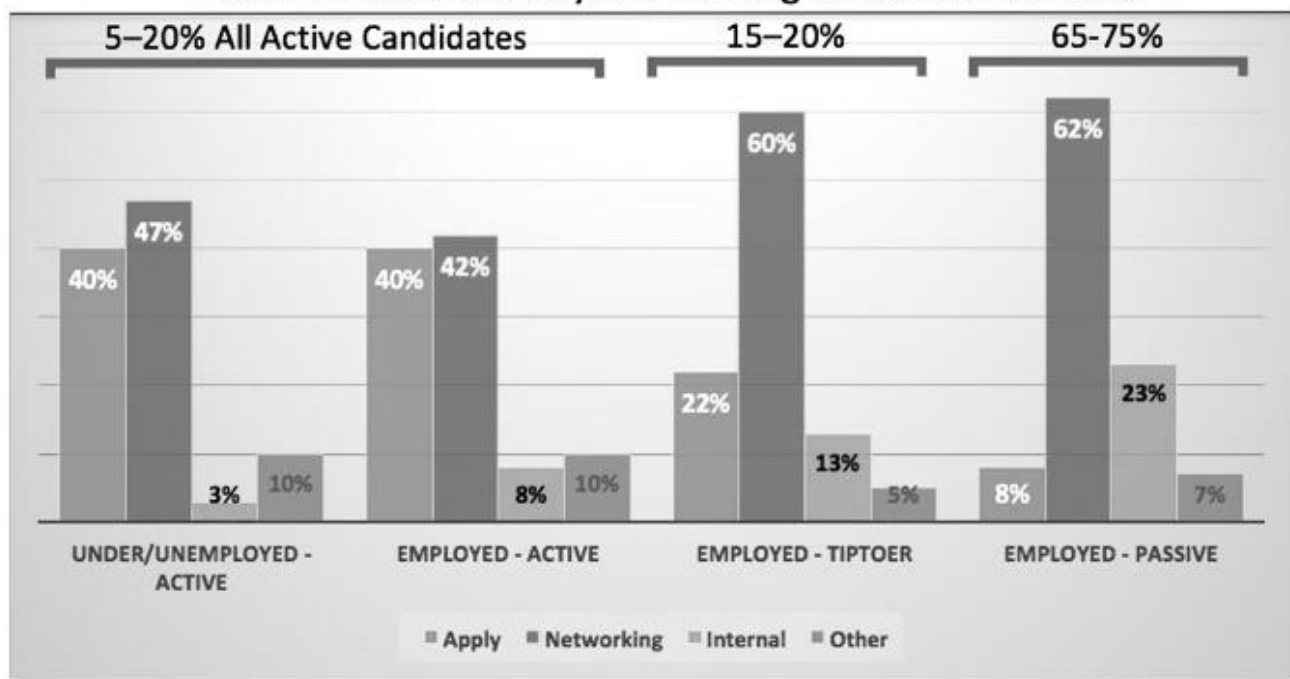

Figure 1. Survey on people found their most recent job Source: Adapted from Lou Adler (2016)

Free features provided by the user platform:

- Professional Identity Management. Creating a user profile that helps to put it in a positive light by adding skills and past experience

- Building and increasing the professional network. The opportunity to invite people, whom the individual knows or wishes to know, to join their network

- Access to information, business details and collaboration opportunities. The ability to post articles or comments and share them in familiar groups

- Multi-platform access. The platform can be accessed from your desktop, mobile, or smartphone

- The premium features you need to subscribe to and pay a monthly fee;

- Talent Solutions through which companies can find suitable candidates for the searchable profile (InMail, Advanced Search)

- Marketing Solutions with which companies or individuals can promote their products within the network (Display Ads, Recommendation Ads) 
- Premium Subscriptions that help companies or individuals organize their profiles better (Sales Navigator, Profile organizer)

Linkedin redefined human resources by bringing it into the digital era, creating new mobile solutions for companies looking for workforce specific to their needs and individuals looking for a job after multiple preferences. The platform has led to changes in managers' behavior and has modernized the selection process for candidates, and it has managed to meet the needs of 4 categories of professionals at the same time:

- Individuals looking for a new job or wanting to establish relationships with people in the same field

- Human resources specialists that help them find the right candidates more easily

- Marketing specialists who can reach a qualified audience and grouped by professional features

- Business collaborators who have access to a professional database

Speaking about Linkedin's influence on candidates and human resources, compared to other sites that create a professional profile, Linkedin is more flexible. Classical Job Platforms (eJobs, BestJobs) that give you the possibility to create a profile alongside a customized CV and apply to various open job ads have a lot of restrictions when it comes to profile customization: you can add to the experience only companies that exist in their database, you have a certain number of characters that you have to observe in order to create a description of the job experience, you cannot communicate with messages with the human resources specialists or others candidates and does not give you the opportunity to add a portfolio.

Linkedin gives you the space and options to add to the company profile you are interested in or noble causes, you can write more about your passions, your hobbies, and whether you are involved in volunteering. Also, a very important aspect in creating an online CV that attracts the attention of employers is the possibility to receive recommendations from former colleagues, collaborators or bosses. They can recommend you for managerial qualities, public speaking, creative writing, critical spirit, etc.

You can post articles on your page, share or share articles / photos / videos posted by someone else on your network. You can send pictures and attachments to those you want to share with. In short, there is another chance to make you known among the people in your field around the world.

From the point of view of human resource specialists, the Linkedin platform facilitates the recruitment process that can be an important consumer of time and resources. The changes this platform brings to the entire process are aimed at actions such as faster sorting of candidates that fit the needs of the company, the ability to contact those candidates via the chat feature to find out more details, which reduces the number of phones, simplifying communication to the company's needs, and eliminating lost dead times through encounters with inappropriate candidates.

Business executives view the Linkedin platform as a way and an opportunity to create a personal brand (Oniga, 2018), communicate directly with people in the same sphere of interest and develop their business. More is a lot of Linkedin events to which a person can take part to learn from the best professionals.

According to a focus group created based on the discussions about the advantages and disadvantages of using Linkedin, the human resources specialist declared that using Linkein is a helpful application in their day-to-day activities.

As advantages, $80 \%$ of the people asked said they faced with other sites that create a professional profile, Linkedin is more flexible.

You can add to the interests of certain businesses or noble causes, you can write more about your passions, hobbies, volunteering. Also, $60 \%$ of the people noticed a very important aspect in creating the online $\mathrm{CV}$ that draws attention - the recommendations. $80 \%$ said that is a major plus that, in the 
Skills category, the same categories of people above can give you a recommendation by clicking on the "+" sign. You can get recommend for managerial skills, public speaking, translation, respect, creative writing, critical spirit etc.

\section{SOCIAL}

Only $4 \%$ of recruiters DON'T use social media in the recruiting process.

$4 \%$ aren't sure, but the $\mathbf{9 2} \%$ of recruiters that do use social media cast a wider net than ever:

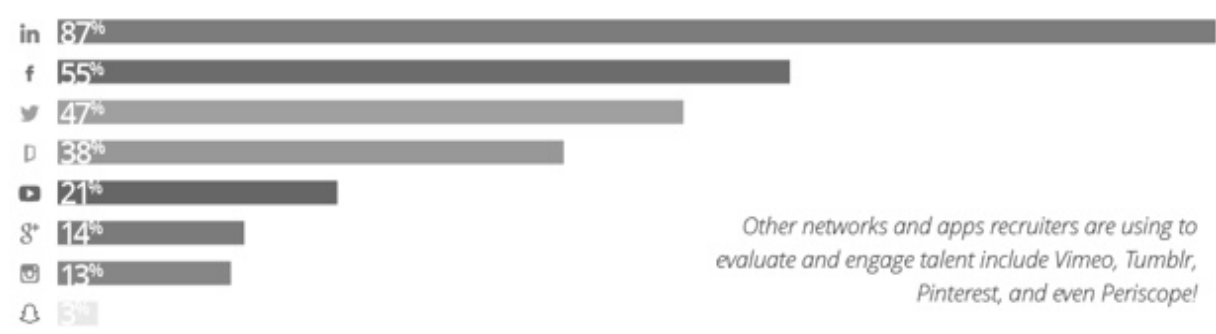

Figure 2. The annual social recruiting survey at Jobvite Source: Adapted from Jobvite, Matt Singer (2015)

On the education side, you can write all the schools, the graduate universities, and below you have a special section where you can introduce extra courses made outside public and / or free education. You are given enough space to write in detail what you have learned, at what time, by what note did you take the exam.

$45 \%$ of the participants at the discussion state that by resembling a social network you can post articles on your page, share or share articles / photos / videos posted by someone else in your network, send pictures and attachments. It has a blog section where you can read articles or even write one to be published. You are still given a chance to make yourself known among the people in your field around the world. English is essential.

Recruiters can post ads for certain posts and may ask their friends to share or send the link to whom they might be interested. $90 \%$ of the users noticed that unlike other social networks, it does not allow the display of an annoying number of advertisements and banners anywhere in the open window. Everything is organized professionally and does not collect data to learn the trend of your users' searches then to show them custom suggestions or ads, like Facebook or any other site that wants to sell something.

Users discovered also some disadvantages. About $20 \%$ of the people affirm that is an uncomfortable situation that any profile you visualize, if you do not have a premium subscription, that person will see that you have seen your profile. If you do not have a premium subscription, you will not see premium people that viewed your profile. You cannot add to your network members with whom you are not connected to the third degree, you cannot see profile pictures in the same situation, you cannot give messages. Notifications are sent very hard on the mail. If you expect something important, it is better to check the site permanently, concluded $70 \%$ of the ones who used the application.

$85 \%$ of the participants said that completing the profile from scratch on your phone can be difficult. This is one of the reasons why some users quit creating their profile after seeing what they have to do or if they feel they do not have too much information to display on a site of this magnitude. 
"Management Perspectives in the Digital Era" 2018

November, 1st-2nd, Bucharest, Romania

Table 1. Advanteges and disadvantages of using Linkedin

\begin{tabular}{|c|l|c|l|c|}
\hline & Advantage & $\mathbf{\%}$ & Disadvantage & \% \\
\hline 1 & Flexible & 80 & Mobile interface & 85 \\
\hline 2 & User friendly & 60 & Privacy notifications & 20 \\
\hline 3 & Multiple functions for users & 80 & $\begin{array}{l}\text { Premium options are available with } \\
\text { payment }\end{array}$ & 80 \\
\hline 4 & $\begin{array}{l}\text { Social networking great } \\
\text { interface }\end{array}$ & 45 & $\begin{array}{l}\text { Delays in communication part of the } \\
\text { application }\end{array}$ & 70 \\
\hline 5 & Good advertising control & 90 & & \\
\hline 6 & Marketing opportunities & 80 & & \\
\hline
\end{tabular}

Source: adapted from Dontigney E., (2018)

As propositions for improving the application and to encourage more people to use it, the human resources specialists recommend that Linkedin should offer more free benefits or even give up the premium options. Paying a monthly or yearly fee makes many users stop using the app due to the lack of opportunities offered for free. For a professional approach to education, you can introduce ways to attach diplomas in the form of PDF images or documents. Because the Facebook network has more users than Linkedin, they can work on a Facebook data import option to attract as many people into this professional environment.

\section{CONCLUSIONS}

The world is constantly changing, and the recruitment process is becoming more and more complex, and recruiters have to adapt to the new digital age. Recruiting is no longer just about removing a vacancy on the labor market. Human resources specialists need to improve their speech, be open and transparent about the company policy they represent, and especially to be present in the online environment, the place where young employees spend most of their time.

In this era, the online environment is the one that convinces and the one who can help you present yourself, as well as an advantage for both parties - candidates and recruiters. Companies are forced to build a professional image just as candidates have to create a complete profile as possible. The way he builds his profile, attention to detail can say more about a candidate than a resume in the classic format, on paper.

For both HR staff and job seekers, Linkedin is the perfect environment for expanding their knowledge and connecting with the right companies. Candidates can apply for jobs, socialize, create a solid, interesting resume, and recruiters can explore the market in a new and interactive way, find out new things about a candidate, chat with him before planning an interview.

The research conducted had some limitations of which the most important is that it can be treated as hasty generalizations, if it's not followed by more complex investigations that can lead to a representative result for the investigated public. The researchers have a very important role in the overall direction of the discussions and how they lead the studies, because they can influence the responses received, even involuntarily.

The online environment is very active and determines important changes in all areas of activity, including in Romania. It is necessary to adapt the outdated processes to the new requirements of the candidates and the education of the specialists is one of the main requirements for the evolution of the labor market.

Last but not at least, for future research, we would like to assess the possibility of realizing quantitative research in order to obtain more accurate, rigorous, statistically representative data. 


\section{REFERENCES}

Adler, L., article on Linkedin, New survey reveals $85 \%$ all jobs filled via networking Retrieved June, 15, 2018 from https://www.linkedin.com/pulse/new-survey-reveals-85-all-jobs-filled-vianetworking-lou-adler/

Challenger, J. A. (2013). Outlook: Hot Jobs for 2018-2025, Challenger, Gray \& Christmas, Inc, Chicago, Retrieved June, 17, 2018 from https://www.challengergray.com/press/pressreleases/outlook-hot-jobs-2018-2025

Digital Natives: A Tech-Savvy Generation Enters the Workplace, Work Design Magazine, Retrieved June, 15, 2018 from https://workdesign.com/2012/02/digital-natives-a-tech-savvy-generationenters-the-workplace/

Dontigney, E. (2018). Disadvantages of Linkedin, Retrieved June, 18 from https://www.techwalla.com/articles/disadvantages-of-linkedin

Edelhauser, E., Ionica, A., Leba, M. (2014). Modern Management Using IT \& C Technologies in Romanian Organizations, Transformations in Business \& Economics, Vilnius University, Lithuania, ISSN 1648-4460, Vol. 13, No 2B (32B), pp. 742-759.

Emilian, R., Tigu, G., State, O., Tulcea, C. (2003). Managementul resurselor umane, Gestiunea carierei angajatilor, Bucharest: Editura ASE.

Fidler, D. (2015). Here's How Managers Can Be Replaced by Software, Harvard Business Review, Digital article, Retrieved June, 17, 2018 from https://hbr.org/product/heres-how-managers-canbe-replaced-by-software/H020W1-PDF-ENG

Morgan, G., (2016). These Will Be the Top Jobs In 2025 (And the Skills You'll Need to Get Them), Fast Company, Retrieved June, 18, 2018 from https://www.fastcompany.com/3058422/thesewill-be-the-top-jobs-in-2025-and-the-skills-youll-need-to-get-them

Noela, A. (2018) Todaysofmag.ro, Inteligența emoțională în era digitala, Retrieved June, 16, 2018 from https://www.todaysoftmag.ro/article/2090/inteligenta-emotionala-in-era-digitala

Oniga, D. \& Zf. Ro (2018). Ce fac executivii de top pe LinkedIn si Facebook, Retrieved June, 16, 2018 from http://www.zf.ro/profesii/ce-fac-executivii-de-top-pe-linkedin-si-facebook$4890786 /$,

Petty, A. (2016). The Balance, blog, Updated September 29, 2016, Retrieved June, 16, 2018 from https://www.thebalance.com/4-essential-skill-sets-for-managing-in-the-digital-era-4092629 